6. While the sero-diagnosis of syphilis in its present condition was not perfect, and owing to its complicated technique and to the difficulty of procuring the necessary ingredients it was limited to a few privileged students, yet it had the indisputable advantage of furnishing us with a rich amount of positive diagnostic data, and the speaker said he considered its adoption in the various hospitals and medical institutions not optional, but absolutely necessary.

\title{
DEMONSTRATION OF WASSERMANN REACTION TEST
}

\section{By Dr. Noguchi, of the Rockefeller Institute}

After demonstrating the Wassermann reaction, Dr. Noguchi showed briefly a reaction evolved by him during some experimentation with the various albumin reactions in the spinal fluids of general paralysis and other disorders. This was obtained as follows: 0.I c.c. of the spinal fluid to be tested is placed in a test-tube whose diameter is $1 \mathrm{~cm}$. or less. To this is added 0.5 c.c. of a ro per cent. solution of butyric acid. The tube is now heated until the fluid is bubbling, and while still hot o.I c.c. of a normal (4 per cent.) solution of sodium hydrate is added. In nearly all spinal fluids an opalescence or cloud occurs, but in the spinal fluid of general paralysis the cloud soon separates into a definite flocculence which is characteristic. The flocculence usually appears in a few momentsrarely requiring more than 20 minutes.

The reaction shown by Dr. Noguchi had the advantage of being positive in a quantity of 0.1 c.c. or less, and of being a qualitative as well as a quantitative test. What the flocculence might mean was not known, but it might consist of some globulin fraction which was found only in syphilitic or meta-syphilitic disorders of the nervous system. That the reaction was not entirely quantitative was shown by the fact that many fluids from non-paralytic cases gave much richer clouds than those from paresis, but the clouds did not flocculate.

Dr. J. W. Moore, of the State Pathological Institute, Ward's Island, said they had tested thus far 80 cases by the Noguchi method. Fifty undoubted cases of paresis gave 48 positive results. The two negative cases did not seem peculiar in any way. Of three cases of cerebral syphilis, two gave positive reactions. Of the non-paralytic cases tested, five were alcoholic psychoses, ten dementia præcox, four epileptic psychoses, two manic-depressive cases, one paranoic state, one imbecile and one case which was diagnosed as Karsakow's delirium, but which proved at autopsy to be due to a fractured skull with extensive diffuse dural hematoma. Only one of the non-paralytic cases gave a positive reaction. This was a case, diagnosed dementia pracox, which had, however, increased knee-jerks and speech defect. Five doubtful cases gave two positive results and three negative.

In the majority of cases of paresis, the Wassermann reaction was also carried out. Four cases of general paralysis which were negative to the Wassermann test were positive to the other. Four gave the Wassermann reaction much less definitely than did the Noguchi reaction. In no case was the Wassermanil test the more conclusive of the two. In two of the cerebral syphilic cases in which the Wassermann reaction was tried it gave a negative result. 
Dr. B. Onuf said that Dr. Castelli had made the statcment that in a large percentage of cascs of general paresis-70 or 80-the Wassermann reaction was positive, and also in about 60 per cent. of cases of senile dementia. Could we conclude from that that senilc dementia was simply a late form of general paresis? That syphilis produced a rather rapid exhaustion of the nervous system, while in senile dementia identical changes occurred in a longer course of time? Did he mean to identify senile dementia with general paresis?

Dr. Boleslaw Lapowski, discussing the Wassermann rcaction, said that on account of its technique and the material and control experiments that it involved, it would always remain a laboratory test. By terming it the "Wassermann reaction" we were inadvertently doing an injury to others who laid the basis of the reaction. Wassermann simply substituted dissolved substances of bacterial extracts of organs instead of emulsions of bacteria, but the basis was the fact discovered by Bordet and Genou, and to them at least some credit was due.

The test was of undoubted value in corroborating or establishing the diagnosis of latent syphilis, but even then it could not always be relied upon, and in dealing with primary or secondary syphilis it was not necessary.

The president, Dr. Sachs, said that while the Wassermann test could not be done at the bedside, its technique was not difficult and could be easily acquired. For the present, of course, this test, as were many others, would be restricted to the laboratory and had to be made by persons who were specially qualified along those lines. Thus far, the reaction had been practically limited to cases of suspected tabes or general paresis, but at the Mt. Sinai Hospital an effort was being made to employ it in other doubtful spinal or cercbral cases where syphilis was suspected.

\title{
PHILADELPHIA NEUROLOGICAL SOCIETY
}

\section{October 23,1908}

The President, Dr. J. W. McConnell, in the Chair

\section{TUMOR OF THE RIGHT INFERIOR PARIETAL LOBULE. OPERATTON; PARTIAL REMOVAL; IMPROVEMENT}

\author{
By F. X. Dercum, M.D.
}

T. G., age 39, single, laborer by occupation, was admitted to the Jefferson Hospital, May 12, I908.

Family History.-Father died of an accident at 45 years of age. Mother died at 50 from tuberculosis. Two brothers and one sister died of tuberculosis.

Personal History.-Does not recall having had the usual diseases of childhood. Has always had good health with the exception of an occasional severe cold. Has used tobacco and liquor moderately. Had gonorrhea ten years ago; no syphilis.

Present Illness.-Three weeks before admission while working, he became suddenly very short of breath and dizzy and fell to the ground; 